\title{
Mrs Killer and Dr Crook: Birth Attendants and Birth Outcomes in Early Twentieth-century Derbyshire
}

\author{
ALICE REID* \\ The Cambridge Group for the History of Population and Social Structure, \\ Department of Geography, Downing Place, Cambridge CB2 3EN, UK
}

\begin{abstract}
After the passing of the 1902 Midwives Act, a growing proportion of women were delivered by trained and supervised midwives. Standards of midwifery should therefore have improved over the first three decades of the twentieth century, yet nationally this was not reflected in the main outcome measures (stillbirths, early neonatal mortality and maternal death). This paper shows that there was a difference in the risks associated with delivery by the different attendants, with qualified midwives having the best outcome, then bona-fide (untrained) midwives and lastly doctors, even when account is taken of the fact that doctors were called in cases of medical need and may have been booked where a problematic delivery was expected. The paper argues that the lack of improvement in outcome measures could be consistent with improving standards of care among both trained and bona-fide midwives, because increased attention to the rules stipulating when midwives called for medical help meant that a doctor was called into an increasing number of deliveries (including less complicated ones), raising the chance of unnecessary and dangerous interventions.
\end{abstract}

Keywords: Midwives, 1902 Midwives Act, Doctors, Maternal Mortality, Neonatal Mortality, Stillbirth

\section{Introduction}

As delivery attendants, Mrs Killer, Mrs Tipler, Mrs Blood and Dr Crook conjure up an image of a team of careless, drink-sodden, disease-spreading, overcharging scoundrels. ${ }^{1}$ Images of birth attendants even up to the early twentieth century have been tainted by such portrayals, fostered by the survival of the traditional untrained birth attendant,

\footnotetext{
* Email address for correspondence: amr1001@cam.ac.uk
}

I would like to thank Eilidh Garrett, Bob Woods and two anonymous referees for helpful comments on earlier versions of this paper. This work was supported by a Wellcome Trust for the History of Medicine PhD studentship, a Research Fellowship from St John's College, Cambridge, with assistance from a British Academy Small Grant [grant number SG:31626], the Population Investigation Committee and the Simon Population Trust.

${ }^{1}$ For Mrs Tipler this image naturally only works if you listen to rather than read the name. 
aloof and condescending trained midwives and interfering doctors who were over-hasty with the forceps and careless with the risk of transferring infection. ${ }^{2}$ In fact, Mrs Killer and her companions were real birth attendants (albeit with unfortunate names) working in the English County of Derbyshire in the early twentieth century. To undertake the regular practice of midwifery these three women should all have been registered by the Central Board of Midwives under the 1902 Midwives Act, following either completion of an approved course of training or having provided proof that they were experienced and of good character. Elizabeth Tipler was a 'bona-fide' midwife: she registered in 1904 with no training, but at least a year's experience and testimony of good character. Frances Killer was a qualified midwife, admitted onto the midwives' roll in 1918, after a course of training. Dr Crook was a male general medical practitioner, but Mrs Blood was uncertified, one of a small but significant number of untrained and unregistered midwives or 'handywomen' who continued to combine delivering infants with post-natal assistance around the house in the early years of the century. ${ }^{3}$ An earlier paper has described the midwifery service in Derbyshire and the changing mix of untrained midwives, trained midwives, doctors and handywomen, and this paper goes on to examine the consequences of booking such delivery attendants in terms of infant and maternal mortality. ${ }^{4}$

\section{Background}

The 1902 Midwives Act introduced the training and regulation of midwives in Britain, and ushered in an era of rapid change in the circumstances of childbirth. At the turn of the century there were few trained midwives available, most women being delivered by a doctor, an untrained handywoman or a combination of the two. Over the following two or three decades a growing corpus of trained midwives gradually took over from handywomen and replaced some of the doctors at delivery, and although some have claimed that this improved midwifery practice most assessments suggest that, in contrast to Sweden and the Netherlands, the training of midwives had little effect on the progress of birth and the survival of infants and mothers. ${ }^{5}$ This may at least partly be due to the slow process of changing a body of untrained midwives to a body of trained midwives, but Woods maintains that there was 'very little improvement' in midwifery between the eighteenth century and the late 1930s, and McIntosh concluded that the Midwives Act had 'more of an impact on doctors' impressions of midwives than on the way midwifery was

\footnotetext{
2 J. Towler and J. Bramall, Midwives in History and Society (Croom Helm, 1986), 131, 169-70; I. Loudon, Death in Childbirth: An International Study of Maternal Care and Maternal Mortality 1800-1950 (Oxford: Clarendon, 1992), 221; N. Leap and B. Hunter, The Midwife's Tale: An Oral History from Handywoman to Professional Midwife (London: Scarlet Press, 1993), 2.

${ }^{3}$ Although there were female doctors by this era, they were still uncommon and all the doctors in this data set used in the course of this paper were male.

${ }^{4}$ A. Reid, 'Birth Attendants and Midwifery Practice in Early Twentieth Century Derbyshire', Social History of Medicine, 25 (2012), 380-99.

${ }^{5}$ Donnison maintained that "there was no doubt that the gradual replacement of the old "bona-fide" midwife by the trained woman had resulted in a great improvement in the general standard of midwife practice' (J. Donnison, Midwives and Medical Men (London: Heineman, 1977), 187). V. De Brouwere, 'The Comparative Study of Maternal Mortality over Time: The Role of the Professionalisation of Childbirth', Social History of Medicine, 20 (2007), 541-62; U. Högberg, 'The Decline in Maternal Mortality in Sweden: The Role of Community Midwifery', American Journal of Public Health, 94 (2004), 1312-20; I. Loudon, 'Midwives and the quality of maternal care', in H. Marland and A.M. Rafferty (eds), Midwives, Society and Childbirth: Debates and Controversies in the Modern Period (London and New York: Routledge, 1997), 180-200: 193-6.
} 
actually practised or the type of women undertaking it'. ${ }^{6}$ Although there has been much written about the professionalisation of midwifery, and there have been a small number of comparisons between the quality of maternal care among different types of delivery attendant, it has rarely been possible to assess the relative quality of care provided by midwives and doctors during the initial years of training and supervision. ${ }^{7}$

Woods, recently, made a case for forms of medical history that focus explicitly on sickness, health and life-chances, forms that explore the effects of health interventions by examining their impact on mortality risks. ${ }^{8}$ Comparisons of trained-and-regulated (qualified midwives), untrained-but-regulated (bona-fide midwives), untrained-andunregulated midwives (handywomen) and doctors are particularly lacking, and this paper attempts to fill that gap by comparing birth outcomes in terms of maternal and perinatal mortality, in order to comment on the effect of training and regulation of midwives on infant and maternal survival in Derbyshire between 1917 and 1922.

\section{The Data}

One of the aims of the Midwives Act of 1902 was to foster conditions for better infant and maternal health through improved delivery practices, and it was part of a series of legislative measures relating to public health, and, more specifically, infant and maternal health, which gathered steam towards the end of the nineteenth century. The 1906 Notification of Birth Act was born of the same concern for the health of the next generation. ${ }^{9}$ This permissive Act allowed local Medical Officers of Health to require that all births (both live and still) be notified within thirty-six hours of birth to enable prompt visiting by trained, local-authority-employed health visitors, who could then advise on the care and the health of the infants and thereby promote better health and higher levels of survival. A second Act in 1915 made notification compulsory, and health visiting was established throughout England and Wales. ${ }^{10}$

The survival of records created by health visitors under the Notification of Birth Act is rare, but this paper uses one such data set. ${ }^{11}$ It consists of copies of the notification

\footnotetext{
${ }^{6}$ R. Woods, 'Lying-in and Laying-out: Fetal Health and the Contribution of Midwifery', Bulletin of the History of Medicine, 81 (2007), 730-59: 758; T. McIntosh, 'Profession, Skill, or Domestic Duty? Midwifery in Sheffield, 1881-1936', Social History of Medicine, 11 (1998), 403-20: 420.

${ }^{7}$ For the background and professional struggle leading up to the 1902 Midwives Act see Donnison, op. cit. (note 5); Towler and Bramall, op. cit. (note 2). For a rare assessment of the quality of maternal care in the UK, see Loudon, op. cit. (note 5). Prior to 1902, there are few systematic records of midwife deliveries, and it is particularly difficult to assess the delivery practices and outcomes of untrained women: those records and accounts which do survive tend to be from literate, educated midwives who regarded themselves as professional, and most are from earlier eras and do not permit assessments of the effect of training on midwifery. For example, see Sarah Stone in R. Woods, Death before Birth: Fetal Health and Mortality in Historical Perspective (Oxford: Oxford University Press, 2009), also A. Tomkins, 'Demography and the Midwives: Deliveries and their Dénouements in North Shropshire, 1781-1803', Continuity and Change, 25 (2010), 199-232. Other accounts are more likely to have been anecdotal and highly selective.

${ }^{8}$ R. Woods, 'Medical and Demographic History: Inseparable?', Social History of Medicine, 20 (2007), 483-503.

${ }^{9}$ D. Dwork, War is Good for Babies and Other Young Children: A History of the Infant and Child Welfare Movement in England 1898-1918 (London and New York: Tavistock, 1987); G. McCleary, The Early History of the Infant Welfare Movement (London: H K Lewis \& Co., 1933).

${ }^{10}$ As with most services provided at a local level, provision varied greatly between local authority areas, and between village, town and city, so numbers of health visitors and percentages of infants visited differed substantially. E. Peretz, 'Maternal and Child Welfare in England and Wales between the Wars: A Comparative Regional Study' (unpublished PhD thesis: Middlesex Polytechnic, 1992).

11 Another such data set has been extensively used by David Barker and colleagues, see D.J.P. Barker (ed.), Fetal and Infant Origins of Adult Disease (London: BMJ Books, 1992).
} 
of births registers for Derbyshire between 1917 and 1922, covering all notified births, supplemented by un-notified births which were then registered, and also by some of the infants who moved to the district some time after birth, and who were found and visited by health visitors. The parallel but legally and practically separate registration of births, for which responsibility lay with parents rather than with birth attendants, allows a check on the completeness of notification, facilitated by the addition to the notification registers of un-notified but registered births. ${ }^{12}$ Some of these births were originally notified to different districts, and once these duplications are removed, and the infants not born in the area are discounted, the numbers of live births in the notification of birth registers tallies extremely well with the numbers of births officially registered in the same districts, placing confidence in the completeness of coverage of the notification registers. ${ }^{13}$ All the information which was required for notification is therefore available: the surname and address of the child, the sex of the child and whether it was still-born, and the name of the midwife or doctor (or both) who delivered the child. The ledgers in which this information was written also include information about the infants gathered by the health visitors at their visits, including the dates and causes of any infant or child death, the occupations of parents, how many rooms there were in the house in which they lived, the number of children previously born to the mother and the number of those who had died. The resulting data set is thus a rich longitudinal source allowing the majority of infants to be traced over the first five or so years of their lives. ${ }^{14}$

The data set covers the rural areas and smaller towns of Derbyshire, and includes 51,376 births over the six-year period. The County Borough of Derby, and the Municipal Boroughs of Chesterfield, Glossop, Ilkeston and Buxton were administered separately and have left no records. The remaining area, however, covered a diverse geographical and economic spectrum: the eastern side of the county was dominated by coal-mining, with cotton manufacture in the central band around Cromford and Matlock, and silk manufacture on the Nottinghamshire border. There was a sizable pottery industry in the south-west, with arable land and the more rugged areas of the peak district in the northwest, where the spa towns of Ashbourne, Matlock Bath and Buxton acted as attractions for the middle classes.

The health visitor data base provides information about infant survival which can be linked to the delivery attendant. Although information on officially registered deaths was provided by local registrars and added to the notification registers, deaths to the few infants moving away or not visited for any reason may have been less likely to have been recorded in the data set, but this can be taken account of by using life table analysis, and related statistical modelling, according to which deaths are related only to the actual life years lived by infants known to be alive in the relevant age groups. Such analysis produces infant mortality rates at every age group very similar to those calculated

\footnotetext{
12 Registration of births, deaths and marriages was introduced in 1837 but births did not have to be registered until six weeks after the birth, hence the rational for a parallel system to allow the visiting of newborn infants.

${ }^{13} \mathrm{It}$ is, of course, possible that some births were missed by both systems, but registration of births is considered to be complete from the $1880 \mathrm{~s}$. See D.V. Glass, 'A Note on the Under-Registration of Births in Britain in the Nineteenth Century', Population Studies, 5 (1951), 70-88. For more assessment of the completeness of this data set, see A. Reid, 'Infant and Child Health and Mortality in Derbyshire from the Great War to the mid-1920s' (unpublished $\mathrm{PhD}$ thesis: University of Cambridge, 1999), 39-45.

${ }^{14}$ Not all infants were visited for five years, and for some visiting stopped much earlier as they moved away, could not be found by the health visitors or were deemed not to need visiting. However, over $95 \%$ of infants received repeated visits. See A. Reid, 'Health Visitors and Child Health: Did Health Visitors have an Impact?', Annales de Demographie Historique, 101 (2001), 117-37.
} 
from registered births and deaths in the area covered by the data set: the early neonatal mortality rate was nineteen per thousand live births, and the late neonatal mortality rate was twelve per thousand live births. ${ }^{15}$ The notification of stillbirths was compulsory, but because stillbirths did not have to be officially registered in England until 1927, the notification register could not be 'topped up' with un-notified stillbirths provided by the local registrars, and it is possible that the notification of stillbirths was deficient. The national stillbirth rate derived from notification, of around thirty per thousand, is considered to be an underestimate of the true rate estimated at around forty per thousand, but the stillbirth rate derived from the data set, at thirty-four stillbirths per thousand births (live and still), suggests that this underestimation might not have been quite as severe in Derbyshire as in England and Wales as a whole. ${ }^{16}$

In comparing the risk of stillbirth among different birth attendants, it is important to consider the possibility that under-reporting may have been concentrated among some types of birth attendants. This might be due to differences either in the understanding of the distinction between live and stillbirths, or in compliance with the notification requirement. Considering the distinction between live and stillbirths, it is well known that legal, medical and religious distinctions between live and stillbirths varied over time and between places, even in the recent past. ${ }^{17}$ The regulation of midwives under the Midwives Act of 1902 should have improved consistency of classification among certified midwives, as they were clearly directed that 'a child is deemed to be stillborn when after being completely born it has not breathed or shown any sign of life'. ${ }^{18}$ Uncertified midwives may, however, have been less clear on the distinction and were in any case less likely to have notified any births at all as this would expose them to the charge of unauthorised practice.

It has been argued that in late nineteenth-century Britain a significant proportion of early neonatal deaths were buried as stillbirths to minimise burial costs or to disguise infanticide. ${ }^{19}$ The absence of a high stillbirth rate suggests that midwives in Derbyshire were not systematically notifying live births as stillbirths between 1917 and 1922, but it is possible that some stillbirths were not notified and that the tendency to notify varied by type of midwife. Stillbirths delivered by uncertified midwives are particularly likely to be missing from the records, unlike live-born infants, whose births may also not have been notified, but who will have been picked up by registration or 'discovered' by health visitors. ${ }^{20}$ It will be argued later in this paper that bona-fide midwives may have been initially less good at following procedure: by the same token they may also have been initially less good at notifying stillbirths. The effect of this will be to decrease stillbirth rates among bona-fide and particularly uncertified midwives, and this will be borne in mind in the analyses which follow.

15 See A. Reid, 'Neonatal Mortality and Stillbirths in Early Twentieth Century Derbyshire, England', Population Studies, 55 (2001), 213-32; 'Infant Feeding and Post-Neonatal Mortality in Derbyshire, England, in the Early Twentieth Century', Population Studies, 56 (2002), 151-66.

16 Woods, op. cit. (note 7).

${ }^{17}$ C. Gourbin and G. Masuy-Stroobant, 'Registration of Vital Data; are Live Births and Stillbirths Comparable All Over Europe?', Bulletin of the World Health Organization, 73 (1995), 449-60; Woods, op. cit. (note 7).

${ }^{18}$ Midwives were further directed to resuscitate any infants born apparently dead (Directions to Midwives, reprinted in the Midwives Roll 1922: xlvi).

${ }^{19}$ G. Mooney, 'Still-births and the Measurement of Urban Infant Mortality Rates c.1890-1930', Local Population Studies, 53 (1994), 42-52.

${ }^{20}$ Because the poor and unmarried were more likely to have been delivered by uncertified midwives (see Reid, op. cit. (note 4)), their rates of stillbirth are also likely to be underestimated. 
The names of delivery attendants, as written in the data set, distinguish between doctors and midwives but do not in general specify whether each midwife was qualified, bona-fide or uncertified. However, this has been ascertained by checking the names of the midwives against the Midwives Rolls which were published biennially by the Central Midwives Board, and which listed all midwives who held a certificate, giving their names, addresses, their unique number, their qualifications (if any), the date they entered onto the roll and whether or not they intended to practice in the coming year. Doctors were identified in the Medical Directory to ascertain the date of their first medical qualification. This paper also uses the Derbyshire County Council Maternity and Child Welfare Committee and Sub-committee Minutes, and Education Committee Minutes which periodically provided names and salaries or subsidies of midwives engaged to work in certain areas of the county. Additional details of the midwifery service and other medical matters were derived from Medical Officer of Health reports for Derbyshire.

\section{Midwifery in Derbyshire}

The 1902 Act was part of the struggle for the regulation of midwives in Britain; it was the first, but by no means the last, piece of legislation regarding midwifery, and introduced the training and supervision of midwives. As a result of the Act, all new midwives had to undergo a course of training and, in order to prevent a sudden dearth of midwives, established midwives without training but with at least a years' experience and proof of good character were permitted to continue to practice if they registered themselves by 1910. Such women were generally known as 'bona-fide' midwives. It was recognised that occasionally, in the absence of a midwife or doctor, someone else would have to deliver an infant and this was not prohibited, but the Act made it clear that from 1905 no woman would be entitled to call herself midwife or be paid for midwifery unless she was certified under the Act. ${ }^{21}$ The Act also introduced rules and regulations regarding equipment, dress, conduct, hygiene and procedures for calling help in a medical emergency.

Following the 1902 Act the balance of delivery attendants gradually changed from untrained bona-fide midwives to trained midwives, with general practitioners losing out to the midwife market. Although there was variation in the speed of change and the development of organised midwifery services across the country, Derbyshire appears to have been fairly typical in the shifting of the balance of delivery attendants. From a roughly even division of births between doctors and midwives in 1909, the proportion of births in Derbyshire attended by doctors fell to just a quarter in 1913, with the share taken by qualified midwives rising from nearly $10 \%$ to almost $25 \% .^{22}$ Over the same period the percentage attended by bona-fide midwives remained fairly static at about $50 \%$, but in the longer term they gradually resigned their share to those with a qualification. ${ }^{23}$ By the immediate post-war period, bona-fide deliveries were falling rapidly, decreasing from about $40 \%$ of births to about $30 \%$ between 1919 and $1921 .^{24}$

Geographical patterns in numbers of bona-fide and qualified midwives over Derbyshire show that urban areas and rural mining areas (which in general were more densely

\footnotetext{
${ }^{21}$ Midwives Act 1902, as reproduced in the Midwives' Roll for 1922.

22 Donnison suggests this is also a product of the draining off of doctors to the war effort in 1914-19, and to the reduced importance of maternity work for doctors as the 1911 Insurance Act made the rest of doctors' income more secure (Donnison, op. cit. (note 5), 185).

${ }^{23}$ Loudon, op. cit. (note 2), 209.

${ }^{24}$ Calculated from Derbyshire Medical Officer of Health Reports for 1919, 1920 and 1921.
} 
populated than rural areas where agriculture dominated) had been better served in terms of midwifery prior to the 1902 Act, and that many of these midwives continued to practise as bona-fide midwives. ${ }^{25}$ As with Britain in general, professional midwives who had invested in a course of training were attracted to the towns which could provide more business without such high travel demands, leaving the agricultural areas relatively poorly served. In 1916 Derbyshire County Council established a county midwifery service, subsidising midwives in sparsely populated areas of the county where there were not enough births to provide a reasonable income for independent midwives. Doubtless this was a useful service, with the added provision of a few small lying-in homes staffed by county midwives. Such homes, however, served only 106 women over the seven-year period (less than $0.25 \%$ ), the majority of whom (95\%) were married women with no particular indication that a problem delivery might have been expected. A further 452 (less than 1\%), mainly married women, took advantage of lying-in homes or hospitals outside the area covered by the data set, such as in Derby and Sheffield, including some women with possible delivery problems. ${ }^{26}$ Sixty-five women, mainly unmarried, delivered in work-houses, but only seventeen of these were in institutions within the area covered. Overall $99 \%$ of women delivered in their own home, and parturient women in remote areas were still more likely to have booked a doctor for delivery indicating that the nearest available midwives were based too far away with, unlike doctors, no access to modes of transport which would allow them to attend quickly and at inconvenient times.

There is good reason to suppose that the vast majority of joint deliveries with a doctor and a certified midwife were cases where the midwife summoned a doctor as a result of medical need. ${ }^{27}$ However, there is also evidence for the continued practice of unqualified midwives or handywomen, and such women were more likely to have delivered with or under the auspices of a doctor. Particularly in agricultural areas, doctors appear to have colluded with uncertified handywomen to allow their illegal delivery of births. In a remote area this could have felt like a benefit to both mother and doctor. The mother would have had the attention of a birth companion from earlier in the labour, for a considerably smaller sum than she would have had to pay the doctor for that much of his time and without the worry about whether the professional birth attendant would arrive in time. The doctor would be able retain the family as clients without having to spend much time at a relatively unprofitable type of case. If necessary he could be summoned when the delivery seemed imminent, but it is likely that often it did not seem worth calling him for the birth itself or that he simply did not arrive in time. ${ }^{28}$

Thus availability of a delivery attendant was a key factor in determining who an expectant mother booked for her delivery. Yet these constraints did not fully determine attendance patterns: there was clearly some choice available to women, with delivery attendants of each sort within reach from almost everywhere in Derbyshire. The research suggests that wealth and perhaps a perception of safety affected the choice of attendant: better off women were more likely to have chosen to be delivered by a doctor and by a qualified midwife rather than a bona-fide one. ${ }^{29}$ The poorest members of society and unmarried mothers sometimes also resorted to handywomen to deliver their infants.

25 Reid, op. cit. (note 4).

${ }^{26}$ Of the forty women delivered in Derby Royal Infirmary, four were recorded as having been delivered by caesarean section.

27 Reid, op. cit. (note 4).

${ }^{28}$ Reid, op. cit. (note 4)

${ }^{29}$ Reid, op. cit. (note 4) 
Loyalty and familiarity also played a part in the choice of attendant: higher parity women, whose oldest children would have been born when there were relatively few qualified midwives, were more likely to have continued to use a bona-fide midwife (maybe the very one who had managed their previous deliveries) for later births. ${ }^{30}$

This period of rapid change when there were still substantial numbers of a variety of delivery attendant of different levels of education, training and outlook is therefore a particularly interesting era, with considerable potential for examining the effects of different types of delivery attendant. Types of midwife and attitudes within groups should not be regarded as static, however. Following 1910, with the natural attrition due to death and retirement, and no possibility of new recruits to this group, the average age of bonafide midwives will have increased. But as older cohorts died out, those remaining will have been more likely to have received at least some education.

Their exposure to the new rules and the regulation systems in place may also have engendered changes in attitudes and practices regarding the birth process. It is clear that although bona-fide midwives were initially less likely than qualified midwives to call for medical help in all the circumstances dictated by the rules, the rigourous inspection system increased their observation of the procedures and the likelihood of making such calls. ${ }^{31}$ It is possible that the advent of trained midwives temporarily increased disparities in the standard of care offered at birth as trained midwives congregated in urban and wealthier areas, but the extent to which trained midwives offered a superior service is not known, nor is the extent to which bona-fide midwives altered their practices as a result of supervision. The speed of change means even a small time series may thus be able to assess the relative impacts of training and supervision of midwives.

\section{Birth Outcomes and Delivery Attendant}

One of the main goals of the Midwives Act of 1902 was to eliminate the 'large amount of grave suffering and fatal disease amongst the poorer classes' which was produced by the lack of public education and inadequate supervision of midwives. ${ }^{32}$ There are many forms of 'grave suffering' which might be produced by poor care at parturition. Injury to the child during birth could have long-term physical or mental consequences, or the mother might sustain injury or infection which could affect her short- or long-term health or well-being. ${ }^{33}$ However, such suffering was not routinely recorded in the notifications of birth data set, even among calls for medical help: generally such cases were only noted in the registers as explanations for stillbirth or infant or maternal death, and most calls for medical help can only be identified in the records by the dual presence of doctor and midwife. ${ }^{34}$ In any case, a call for medical help does not necessarily imply poor management of labour nor a poor outcome: circumstances such as malpresentation will inevitably occur, the most common of which, such as breech, can be managed successfully despite higher risks to mother and child. In this data set therefore the only reliable indicators of poor management of labour are stillbirth and early neonatal and maternal

\footnotetext{
${ }^{30}$ Reid, op. cit. (note 4).

${ }^{31}$ Reid, op. cit. (note 4).

32 General Medical Council, 1889, quoted in Towler and Bramall, op. cit. (note 2), 166.

${ }^{33}$ E. Fox, 'Powers of Life and Death: Aspects of Maternal Welfare in England and Wales between the Wars', Medical History, 35 (1991), 328-52: 350.

${ }^{34}$ Eighty-eight per cent of the cases where reasons for medical help were noted were associated with a death to the mother or child.
} 
death, and although these are crude measurements, responding to only the most extreme cases, they still enable comparison of the different categories of delivery attendant. Of course there can be many influences on the risk of stillbirth, maternal or infant death which have nothing to do with the management of the labour, and some factors associated with the choice of a bona-fide midwife, such as lower social class, might be expected to be associated with a higher risk of stillbirth or early neonatal death. Therefore, in order to assess the influence of different attendants on birth outcomes, while holding such other factors constant, it is necessary to perform multivariate analyses.

Before reporting on the analyses, Table 1 shows descriptive statistics for the births in the data set. The first two numerical columns show the numbers and percentages of all births, and the second two show the figures for those infants included in the analyses. The following analyses exclude all those born outside the district and those without indication of delivery attendant as these births will have been notified elsewhere, or not at all. Information about any stillbirths and early neonatal deaths is less likely to have been transferred to the notifications register and such infants are therefore overwhelmingly selected for survival. Those without contextual socio-economic information are also excluded: this covers infants who were not visited either because they could not be found, did not want visiting, were deemed not to need visiting or from whom complete information was not gained. Stillbirths and infant deaths are over-represented in this group, but comparative analyses including such infants and controlling for missing values produced almost identical results to the analyses shown, which are simpler to interpret. Most aspects of Table 1 do not require specific comment, but the large number of infants in social class three can be attributed to the dominance of the skilled manual labour of miners, and the increase in the number of births in 1919 and 1920 is not simply the result of demobilisation, but also the adoption of notification of the area around Chesterfield and thus wider coverage of the data set.

Table 2 shows the odds ratios, derived from multivariate logistic regressions, associated with various influences for the risks of an infant being stillborn, dying in the early neonatal period, dying in the late neonatal period and of the mother dying within six weeks of giving birth. ${ }^{35}$ The odds ratios for the various combinations of delivery attendant are shown towards the bottom of the table. The other variables are mainly included as control variables, and show expected results such as baby boys, twins, first births and higher parity

\footnotetext{
35 Although the period included in studies of maternal death ranges from thirty to sixty days, the convention followed here is forty-two days (six weeks) which captures most of the direct and indirect maternal deaths but not too many deaths which are unrelated to pregnancy and birth (see S. Curtis, 'Midwives and their Role in the Reduction of Direct Obstetric Deaths During the Late Nineteenth Century: The Sundsvall Region of Sweden (1860-1890)', Medical History, 49 (2005), 321-50: 326; R. Schofield, 'Did the mothers really die? Three centuries of maternal mortality in the world we have lost', in L. Bonfield, R.M. Smith and K. Wrightson (eds), The World We Have Gained: Histories of Population and Social Structure (Oxford: Blackwell, 1986), 231-60: 234; I. Loudon, 'Deaths in Childbed from the Eighteenth Century to 1935', Medical History, 30 (1986), 1-41), and goes some way towards making sure that all maternal deaths are included, even those 'hidden' by a medical practitioner ascribing them to some other cause (Loudon, op. cit. (note 2), 36). In addition, not all of the deaths to mothers had a cause noted rendering it necessary to use a 'time since birth' rather than an 'obstetric causes' definition of maternal mortality. In this data set, 142 mothers were noted in the records as having died within six weeks of delivery, and a further seventy-one were noted as having died but with no date given: it is likely that most of these seventy-one did die within six weeks, as the maternal mortality rate is twenty-nine deaths per ten thousand deliveries when they are not included and forty-three when they are included, which is precisely the level in England and Wales as a whole at this time, and indeed for the county of Derbyshire (I. Loudon, 'Maternal Mortality: 1880-1950. Some Regional and International Comparisons', Social History of Medicine, 1 (1988), 183-228: 186, 207).
} 
All infants in data set Number Percentage

Number of infants

Sex

\section{Female}

Male

Missing

Multiplicity of birth

Singleton

Twin/triplet

Birth order

1 st birth

2nd or 3rd birth

4th birth or higher

Missing

Legitimacy

Legitimate

Illegitimate

Mother's work status before the birth

Not working

Working

51376

24526

50019

13968

49961
1415

50082

Class 2

Class 3

Class 4

Class 5

Other or not known

Urban or rural area

Rural

Urban

36052

Not mining

Mining

Season of birth
Summer months

Other months

Birth year
1917
1918
1919
1920
1921
1922

Birth attendant

Doctor only

Both doctor and midwife

Midwife only

No information

21242

41.35

58.49

30052

3561

3643

7880

13681

11831

10780

6.93

7.09

15.34

26.63

23.03

20.98

11886

4882

23.14

9.50

31801

2807

61.90

5.46

Births to midwives of different qualifications
Qualified
Bona-fide

20142

Other
39.21

29.27

2.91
26203

647

47.74

51.00

1.26

1357

97.36

2.64

15593

16473

5342

27.19

30.35

32.06

10.40

97.25

2.75

97.48

1294

2.52

205

4481

27461

6776

4811

7642

0.40

31013

20363

60.36

39.64

$15324 \quad 29.83$

29.83
70.17

Infants used in analysis*

Number Percentage

43274

$20943 \quad 48.40$

$22331 \quad 51.60$

$42114 \quad 97.32$

$1160 \quad 2.68$

$12722 \quad 29.40$

$14691 \quad 33.95$

$15861 \quad 36.65$

$42226 \quad 97.58$

$1048 \quad 2.42$

$42179 \quad 97.47$

$1095 \quad 2.53$

$146 \quad 0.34$

$4063 \quad 9.39$

$26049 \quad 60.20$

$6292 \quad 14.54$

$4354 \quad 10.06$

$2370 \quad 5.48$

$25677 \quad 59.34$

$17597 \quad 40.66$

$11999 \quad 27.73$

$31275 \quad 72.27$

$17902 \quad 41.37$

$25346 \quad 58.57$

$3176 \quad 7.34$

$3148 \quad 7.27$

$6042 \quad 13.96$

$11363 \quad 26.26$

$10188 \quad 23.54$

$9357 \quad 21.62$

$10047 \quad 23.22$

$4129 \quad 9.54$

$29098 \quad 67.24$

$\begin{array}{lrr}1493 & 2.91 & 1290\end{array}$

Table 1: (Continued on next page) 


\begin{tabular}{ccc} 
All infants in data set & \multicolumn{2}{c}{ Infants used in analysis* } \\
Number Percentage & Number Percentage
\end{tabular}

Events

$\begin{array}{ll}\text { Stillbirths } & 1710 \\ & 1275\end{array}$

Early neonatal deaths $\quad 951 \quad 640$

Late neonatal deaths $\quad 579 \quad 441$

$\begin{array}{lll}\text { Maternal deaths } & 142 & 99\end{array}$

Source: Derbyshire notifications of birth data set.

* Excluding infants not born in area, and those without sex, parity or without either a father's occupation or an indication of illegitimacy.

Table 1: Descriptive statistics of infants included in the data set: Derbyshire 1917-22.

infants being at higher risk of stillbirth and early death. Infants born to the higher social classes were less likely to have been stillborn, and the risk of both stillbirth and death in the first few days of life was higher for the children of women who worked during their pregnancy. The infants of unmarried mothers, however (many, but not all of whom worked), showed no increased risk of death until the later neonatal period. ${ }^{36}$ There was a slightly increased risk in the early neonatal period for urban dwellers, and a higher risk of stillbirth for those living in mining districts. Those born in the summer months (May to September) were less likely to have died shortly after birth, and there was a higher risk of stillbirth during the 1918-19 influenza epidemic. ${ }^{37}$ Maternal deaths were more common following the births of twins, among primiparae and during the flu epidemic. Over time, the risk of late neonatal mortality declined, but the risk of stillbirth increased. It is possible the latter is due to improving notification rather than a real rise in the risk.

In addition to the influences of these factors, and even when they are controlled, the choice of delivery attendant was associated with a fairly large risk and distinctive patterns. On the assumption that most cases of joint doctor and midwife delivery were cases of medical help, it is unsurprising that such cases suffered a higher risk of an infant death or stillbirth: where the midwife was certified (ie. qualified or bona-fide) the chances of a stillbirth were nearly four to five and half times as high as where a qualified midwife delivered on her own, and the chances of an early neonatal infant death were two to two and a half times as high. It is slightly more difficult to interpret the risks associated with uncertified midwives (handywomen), as their numbers were so small and statistical significance was therefore lower; nevertheless, deliveries attended by both doctor and uncertified midwife had risks very similar to those associated with doctors on their own, a further suggestion that such cases should not be treated as emergency or high risk

\footnotetext{
36 The lack of an illegitimacy penalty for perinatal mortality may be due to the possible omission of births to uncertified midwives, who may have provided a service for unmarried mothers. However, the delayed effect of illegitimacy on mortality has also been found elsewhere (E.A. Wrigley, 'Births and Baptisms: the Use of Anglican Baptism Registers as a Source of Information About the Numbers of Births in England before the Beginning of Civil Registration', Population Studies, 3 (1977), 281-312).

${ }^{37}$ For an exploration of the effect of influenza during pregnancy on the risk of stillbirth and infant mortality, see A. Reid, 'The Effects of the 1918-1919 Influenza Pandemic on Infant and Child Health in Derbyshire', Medical History, 49 (2005), 29-54.
} 


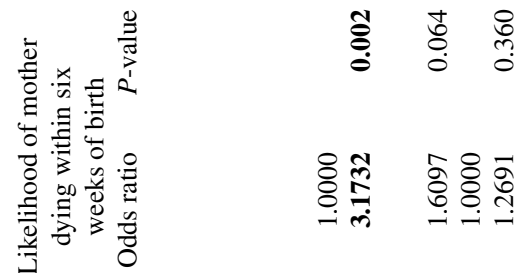

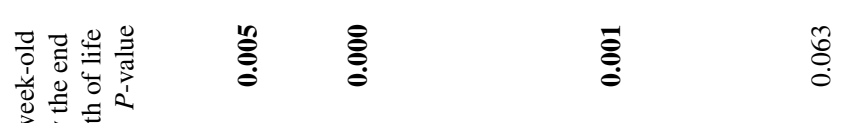

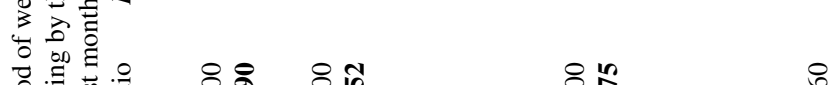

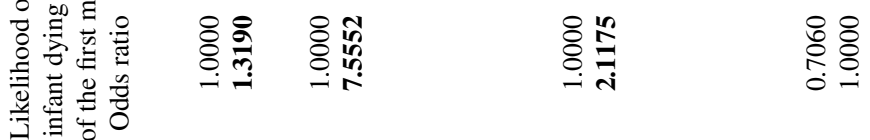

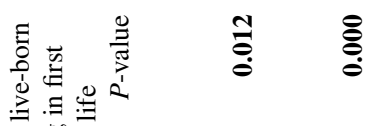

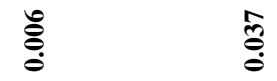

实总

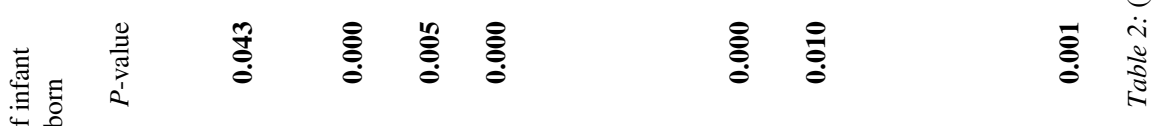

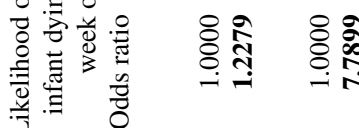

务芯

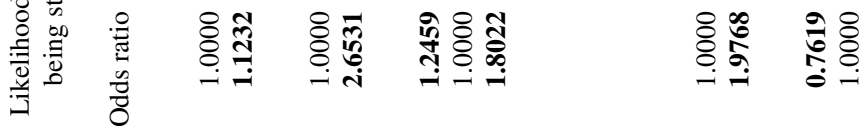

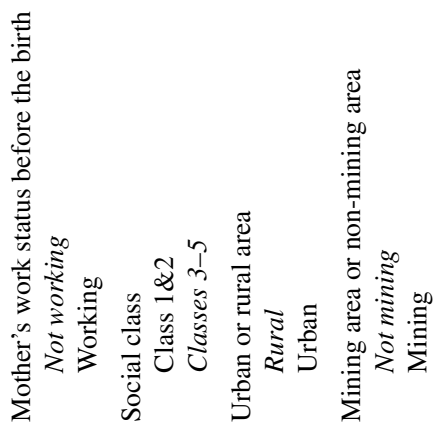




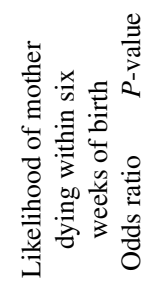

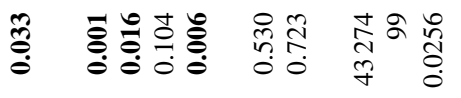

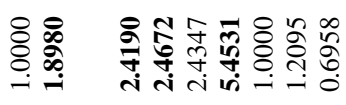

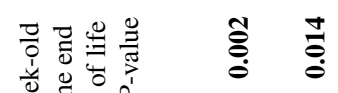

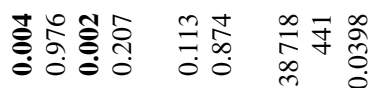

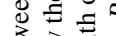

3 家言

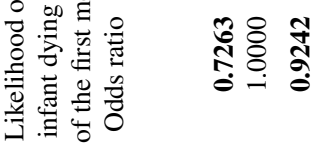

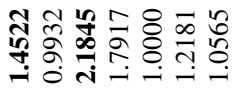

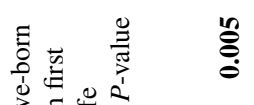

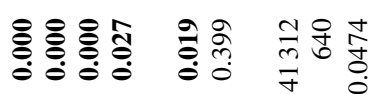

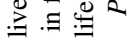

잉

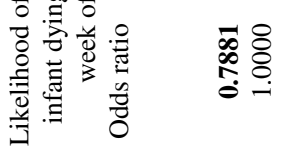

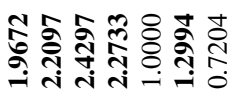

तิ

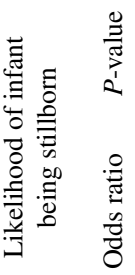

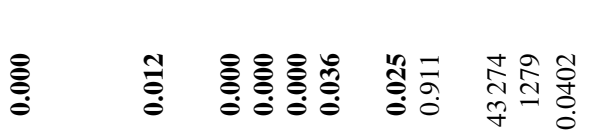

สำ

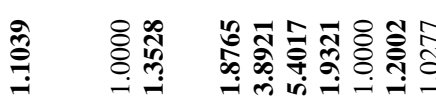

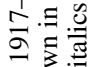

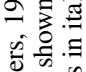

离的.

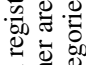

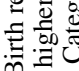

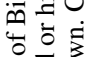
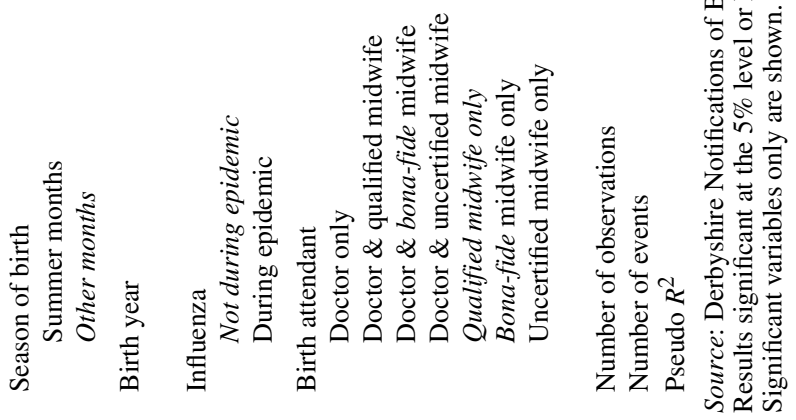
cases, and that many doctors apparently delivering on their own actually had the help of a handywoman to manage most of the labour. ${ }^{38}$

It is clear that we can treat certified midwife and doctor joint deliveries as "problem deliveries' where medical help was necessary, but this does not necessarily imply that all other deliveries were 'uncomplicated'. ${ }^{39}$ The regulations under the Midwives Act stipulated firmly that 'in all cases of illness of the patient or child, or of any abnormality occurring during pregnancy, labour, or lying-in, a midwife, as soon as she becomes aware thereof, must call in to her assistance a registered medical practitioner'. ${ }^{40}$ The list of conditions necessitating medical help is long, and ranges from death or apparent death, through presentations other than the uncomplicated head or breech, excessive bleeding, incomplete expulsion of the placenta within two hours after birth, abdominal swelling or tenderness in the postpartum woman to dangerous feebleness in the child and 'discharge from the eyes, however slight'. ${ }^{41}$ Midwives were further bound to notify the local supervising authority of calls for medical help, deaths of mother or child before the attendance of a registered medical practitioner, stillbirths, liability to be a source of infection (usually as the result of contact with a case of puerperal fever or other infectious condition) and where the mother proposed to substitute artificial feeding for breast feeding.

Some of the reports of the Derbyshire Medical Officer of Health provide the numbers of calls for medical help under various categories and these are shown for 1919, 1920 and 1921 in Table 3, demonstrating that the increase in such calls over the three years was due to an increase in cases of retarded labour, lacerated perineum and abnormal presentations. It is unlikely that retarded labour and abnormal presentations would naturally increase over time, so it is probable that midwives became more likely to summon help for cases such as these, with either more midwives summoning help or midwives broadening the criteria or the range of the cases for which they were prepared to call for help.

Table 4 shows that bona-fide midwives in Derbyshire were less likely to have called for help than qualified midwives, but it also shows that with each successive year they became more likely to have done so. ${ }^{42}$ Contemporary observers noted the increase in medical help calls by midwives in general and ascribed it to newly trained midwives suffering from 'a lack of experience and a failure to take responsibility' and being 'less self-reliant than [their] shorter trained predecessor[s]' ${ }^{43}$ However, it has become more usual to interpret high rates of medical aid as a sign of alert midwifery and attention to the guidelines laid down for midwives to follow. ${ }^{44}$

\footnotetext{
${ }^{38}$ Midwives known to be uncertified delivered only 202 births in total, of which 131 were with a doctor.

${ }^{39}$ The evidence for treating joint deliveries with certified midwives as 'problem deliveries' is derived from comparisons with Medical Officer of Health reports, see Reid, op. cit. (note 4).

40 Midwives Roll 1922, xlv.

41 In contrast to Britain today, in the early twentieth century simple breech presentations were regarded as uncomplicated and suitable for vaginal delivery by a midwife on her own.

${ }^{42}$ See also A. Newsholme, 44th Report to the LGB 1914-15, Cd 8085 XXV (London: HMSO, 1914-15), 81. See also Dr M'Gonigle's comment in the discussion following A. Topping, 'Maternal Mortality and Public Opinion', Public Health, 49 (1936), 342-49: 349.

${ }^{43}$ J. S. Fairbairn, 'The Maternal Mortality in the Midwifery Service of the Queen Victoria's Jubilee Institute', BMJ (1927), 47-50: 48 .

${ }^{44}$ Fox, op. cit. (note 33), 341; P. Dale and K. Fisher, 'Implementing the 1902 Midwives Act: Assessing Problems, Developing Services and Creating a New Role for a Variety of Female Practitioners', Women's History Review, 18 (2009), 427-52: 440 .
} 


\begin{tabular}{|c|c|c|c|}
\hline & 1919 & 1920 & 1921 \\
\hline Abortion/miscarriage & 70 & 73 & 74 \\
\hline Varicose veins & 3 & 2 & 2 \\
\hline Ante-partum haemorrhage & 35 & 47 & 38 \\
\hline Deformed pelvis & 15 & 9 & 16 \\
\hline Discharge during pregnancy & 4 & 2 & 1 \\
\hline Retarded labour & 203 & 298 & 321 \\
\hline Retained placenta & 44 & 54 & 63 \\
\hline Abnormal presentation & 63 & 106 & 124 \\
\hline Lacerated perineum & 86 & 163 & 157 \\
\hline Stillbirth & 18 & 26 & 26 \\
\hline Rise of temperature & 27 & 42 & 27 \\
\hline Post-partum haemorrhage & 21 & 16 & 22 \\
\hline White leg & 4 & 5 & 10 \\
\hline Inflammation of the breast & 1 & 1 & 1 \\
\hline Fits/convulsions & 5 & 8 & 3 \\
\hline Puerperal insanity & 4 & 0 & 1 \\
\hline Prolapse of cord & 1 & 8 & 3 \\
\hline Injuries/malformations & 21 & 26 & 18 \\
\hline Dangerous feebleness of child & 120 & 128 & 126 \\
\hline Eye conditions & 63 & 69 & 64 \\
\hline Skin eruptions & 2 & 5 & 3 \\
\hline Condition of naval & 7 & 5 & 2 \\
\hline Miscellaneous & 72 & 159 & 147 \\
\hline Total & 889 & 1252 & 1249 \\
\hline Medical help as percentage of midwife deliveries & 9.35 & 10.24 & 11.39 \\
\hline Medical help as percentage of all deliveries & 7.51 & 8.04 & 8.66 \\
\hline
\end{tabular}

Table 3: Medical help calls by midwives in Derbyshire, 1919-21.

Lower rates of medical help calls among bona-fide midwives probably reflect histories of self-reliance and the limiting of medical aid calls to life-threatening situations. ${ }^{45}$ They will have been encouraged by the Derbyshire inspectors of midwives, who were assiduous in their duties, paying an average of over two visits to each midwife each year, to broaden the range of cases and severity of conditions for which they sought medical aid. ${ }^{46}$ The inspectors clearly felt that such visits and discussions were beneficial, finding a progressively higher proportion of midwives good rather than satisfactory, indifferent or bad, and the concentration on raising standards among bona-fide midwives could mean such women were responsible for much of the increase in medical help calls for retarded

\footnotetext{
${ }^{45}$ Lower rates of medical help calls among bona-fide midwives might also arise if such midwives were less likely to have been booked for deliveries where women considered themselves to be at risk. Previous research using this data set, however, indicates that although women who had suffered a previous stillbirth were slightly more likely to have booked a doctor, there was no effect on the choice of qualified or bona-fide midwife (see Reid, op. cit. (note 4))

46 J. Campbell, Report on the Physical Welfare of Mothers and Children. England and Wales. Volume Two (London: The Carnegie United Kingdom Trust, 1917), 62. For more detail on inspections, see Dale and Fisher, op. cit. (note 44) and J. Mottram, 'State control in local context: public health and midwife regulation in Manchester, 1900-1914', in H. Marland and A.M. Rafferty (eds), Midwives, Society and Childbirth: Debates and Controversies in the Modern Period (London and New York: Routledge, 1997), 134-52.
} 
สู

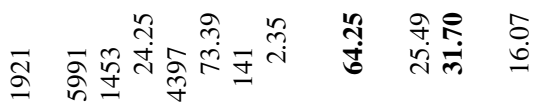

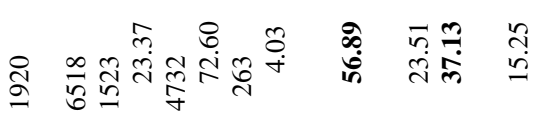

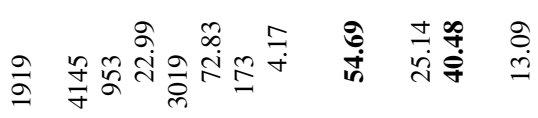

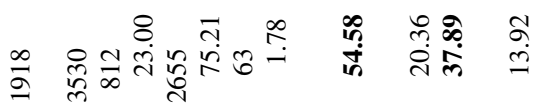

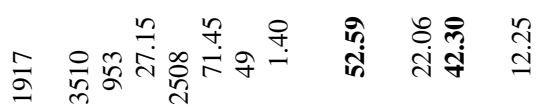


labour, abnormal presentation and retained placenta. ${ }^{47}$ The pattern of fewer medical help calls by bona-fide midwives could therefore explain the apparently higher risks of adverse outcomes for such attendants than qualified midwives both in conjunction with a doctor and on their own: the former because only the highest risk patients were concentrated into the medical help group, and the latter because their sole deliveries still contained some 'complicated deliveries' at slightly higher risk. Delivery by an uncertified midwife on her own does not appear to have carried significantly higher risks than delivery by a qualified midwife. This counter-intuitive result is likely to be due to the fact that such midwives will have been reluctant to notify births for fear of prosecution for unauthorised practice, and many of their deliveries are likely to have been attributed to doctors or to no birth attendant at all. ${ }^{48}$

It is assumed that where only a doctor's name was mentioned in association with a birth, a doctor had been booked for delivery, and Table 2 shows that expectant women in this position were also more likely to have suffered a poor outcome. In comparison to deliveries by a qualified midwife on her own, infants delivered by a doctor on his own were over $80 \%$ more likely to have been stillborn or to have died in the first week of life, and still nearly $50 \%$ more likely to have died in the rest of the first month of life. The women themselves were also over twice as likely to have died. This appears to suggest that it was a bad idea to book a doctor for delivery; however, we must bear in mind the possibility that risk status and delivery attendant were not independent: women with reason to think they might encounter a problem may have been more likely to have booked a doctor.

One of the indications of poor outcome would be a previous stillbirth, and multiparous women who had suffered a previous stillbirth were $10 \%$ more likely to have booked a doctor. $^{49}$ If this additional risk were to explain the higher risk associated with booked doctors, then it would be expected that inclusion of a control for previous stillbirth would decrease the odds ratio associated with doctor delivery. Such a model (not shown) indicates that a previous stillbirth is associated with a significantly increased risk of stillbirth or neonatal death, but that controlling for this does not alter the risks associated with a doctor delivery, so the tendency of women expecting problems to book a doctor cannot explain the poorer outcomes for doctors. Although there will be many other indicators of a high risk birth which we cannot detect through the information available in this data set, if all the disadvantage of a doctor was associated with the grouping of high risk births to him, one would expect some diminution of the risk when some part of this was controlled for.

However, a certain percentage of women booking a doctor for delivery will have had unforeseen complications, similar to those for which a midwife would have to call for a doctor's aid. Over the six-year period qualified midwives appear to have summoned medical help for $23 \%$ of deliveries, and these cases were 3.9 times more likely to have resulted in a stillbirth. If we assume that the same percentage of doctors' cases were subject to this additional risk and that the rest were subject to the same risk as sole deliveries by qualified midwives, we can calculate a weighted mortality risk for doctor deliveries of 1.7 - in other words unforeseen complications in doctor-booked deliveries would raise the risk of stillbirth to $70 \%$ higher than for qualified midwives who did not need to call for a doctor. This is not far different to the observed penalty for doctors, but doctor-booked

\footnotetext{
${ }^{47}$ Derbyshire Medical Officer of Health reports. For more details, see Reid, op. cit. (note 4).

${ }^{48}$ In addition, this group of midwives may also include some certified midwives who could not be found in the midwife rolls because they were practising in the district for only a short time or because mis-transcription prevented links being made.

${ }^{49}$ Reid, op. cit. (note 4).
} 
deliveries still carried an additional $20 \%$ higher chance of a stillbirth, an additional $70 \%$ higher chance of an early neonatal death, a $45 \%$ higher chance of a late neonatal death and an additional $100 \%$ higher chance of a maternal death. The combination of doctors and uncertified midwives was even more dangerous for perinatal and maternal mortality, with women delivered by this combination being over five times more likely to have died than those delivered by a qualified midwife only.

The danger of causing a puerperal infection by transmission from other patients was already well known, and every certified midwife had to follow procedures to minimise the risks, including scrupulous cleanliness of herself and her clothes, disinfection of hands, instruments and swabs before contact with the generative organs of the patient, and temporary suspension from practice after contact with an infectious disease. ${ }^{50}$ Doctors did not have to follow such strict procedures, were more likely to perform vaginal examinations and unnecessary interventions in the interests of a speedy delivery, and it has been suggested that they were generally more lax in their cleanliness despite having probably come into contact with far more cases of infection than midwives. ${ }^{51}$ It was clear from the statistics gathered that maternal mortality was higher among doctors' than midwives' cases, and this is confirmed by the notifications of puerperal fever in Derbyshire, which are shown in Table 5. Cases among midwife-booked deliveries (which included medical help calls) increased during this period, while those among doctorbooked deliveries fluctuated considerably, but stayed consistently and significantly well above those for midwives.

Bona-fide midwives were around $20 \%$ more likely to have been associated with stillbirth and infant death than qualified midwives, but no more likely to have been associated with a maternal death (Table 2) and show no significant differences in notifications of puerperal fever (Table 5).

\section{Conclusions}

After the passing of the 1902 Midwives Act, a growing proportion of midwives were trained, and almost all were subject to supervision and advice over conduct and treatment of difficult cases. With the gradual retirement of the bona-fide midwives and the stepping back of doctors from midwifery work, more women were delivered by midwives with a specific course of training. Standards of midwifery should therefore have improved over the first three decades of the twentieth century, yet nationally this was not reflected in the main outcome measures (stillbirths, early neonatal mortality and maternal death). Nevertheless, this paper has shown that there was a difference in the risks associated with delivery by the different attendants, with qualified midwives having the best outcome, then bona-fide midwives and lastly doctors, even when account is taken of the fact that doctors were called in cases of medical need and may have been booked where a problematic delivery was expected.

Donnison suggests that 'improvements in midwifery practice [among midwives] were offset by a decline in standards of midwifery in general practice as general practitioners delivered fewer and fewer births and gradually lost the experience of normal labours

\footnotetext{
${ }^{50}$ Midwives Roll (1922), xlii-li. In 1916, twenty-seven Derbyshire midwives were temporarily suspended from practice for being a possible source of infection. Sixteen of these were related to puerperal fever: of the others, five were cases of scarlet fever (Derbyshire Medical Officer of Health Report, 1916).

${ }^{51}$ Loudon, op. cit. (note 5), 185, 196; Loudon, op. cit. (note 2), 186, 218-23; I. Loudon, 'Puerperal Fever, the Streptococcus and the Sulphonamides, 1911-1945', BMJ, 295 (1987), 485-90.
} 


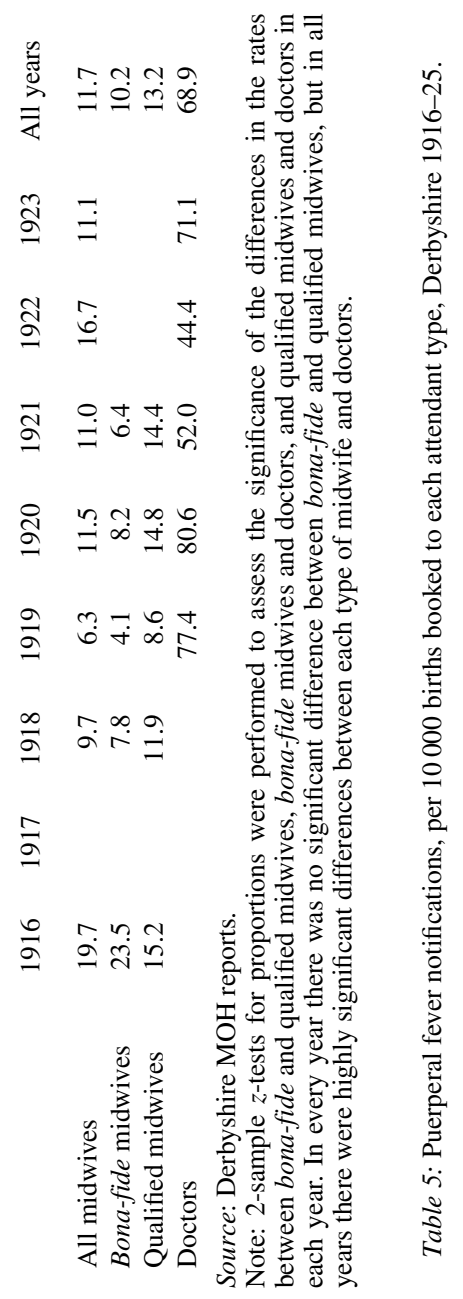


which is a necessary preliminary to the understanding and treatment of abnormal ones', but Pantin argues the opposite: that doctors' expansion into midwifery at the expense of midwives, together with higher intervention, caused maternal mortality to increase. ${ }^{52}$ This paper offers more support for a decline in doctors' midwifery bookings than an increase, and suggests that qualified and careful midwives such as Mrs Killer were taking charge of an increasing number of births, and that bona-fide midwives such as Mrs Tipler, although declining in numbers, were improving in practice, at least to the extent that they were increasing their adherence to the guidelines of the Central Midwives Board. The stubborn refusal of maternal mortality rates to improve therefore continues to be a puzzle, but it is not necessary to argue for a decline in doctors' midwifery standards: the paradox can be explained by the fact that midwives were not allowed to use instruments in delivery and had to call a doctor for any abnormal event. ${ }^{53}$

Increases in calls for medical help (primarily fuelled by bona-fide midwives) will have increased the chances of intervention, use of instruments and transfer of infection. This is not to imply that intervention in medical help calls was inevitable, but other evidence suggests that about half of all calls for difficulties or delays in labour around this time led to forceps deliveries. ${ }^{54}$ Such practices were not only more likely when a doctor was present because he was allowed to perform them, but a doctor was also more likely to interfere when there was a perception of medical need. ${ }^{55}$ While doctors might have been at higher risk of infecting any woman or infant through increased contact with infection and less rigourous attention to hygiene, the risk of infection was particularly high following surgical intervention or where a woman was already weakened or losing blood. ${ }^{56}$ Thus, even though there were fewer doctors booked for delivery, and therefore a smaller chance of unnecessary interventions, doctors attended a growing proportion of medical need cases, where the chance of intervention and infection was greater, keeping up the stillbirth, early neonatal mortality and maternal mortality rates. We can speculate that if midwives had been allowed to manage a wider range of difficult births themselves, and had been trained in the use of instruments, as in Sweden, then outcomes would have been better.

\footnotetext{
52 Donnison, op. cit. (note 5), 190; C.G. Pantin, 'Maternal Mortality and Midwifery on the Isle of Man, 1882 to 1961', Medical History, 40 (1996), 141-72: 160.

53 Although overall a doctor was booked for fewer deliveries, there was considerable variation and many doctors maintained midwifery case loads as high as many of the rural midwives. See Reid, op. cit. (note 4).

${ }^{54}$ Fairbairn, op. cit. (note 43), 48.

55 Fox, op. cit. (note 33), 340.

${ }^{56}$ I. Loudon, The Tragedy of Childbed Fever (Oxford: Oxford University Press, 2000), 6.
} 